\title{
Comparison of effects of nifedipine and ritodrine on maternal and fetal blood flow patterns in preterm labor
}

\author{
Baran Özhan Baykal', Sümeyra Nergiz Avcıŏglu ${ }^{2}$ \\ ${ }^{1}$ Department of Obstetric and Gynecology, Batman Medikal Park Hospital, Batman, Turkey \\ ${ }^{2}$ Department of Obstetrics and Gynecology, Adnan Menderes University Faculty of Medicine, Aydin, Turkey
}

\section{Abstract}

Objective: The aim of this study was to investigate and compare the effects of nifedipine and ritodrine treatment on fetomaternal blood flow parameters in women with preterm labor.

Material and Methods: Sixty women with gestational age between 24 and 36 weeks admitted to the obstetrics clinic for preterm labor were enrolled in this study. Patients were randomly assigned to receive either nifedipine $(n=30)$ or ritodrine $(n=30)$ treatment. Demographic features, clinic and laboratory parameters, fetal and maternal side effects, and Doppler ultrasound indices of the umbilical artery (UA), uterine arteries (UtA), and middle cerebral artery (MCA) before, 2 hours after, and 48 hours after the initiation of tocolytic treatments were compared between the two groups.

Results: In both the groups, early- and late-onset changes in the pulsatility index (PI) and other Doppler indices for UA, UtA, and MCA were similar. In addition, time elapsed till delivery, fetal mortality, and maternal morbidity in both the groups were not statistically significant ( $p>0.05)$. However, maternal side effects such as tachycardia was more frequent $(\mathrm{p}<0.05)$ in the ritodrine group. Besides, in the ritodrine group, anxiety was only minimally observed.

Conclusion: Nifedipine and ritodrine used as tocolytic agents did not significantly alter early- and late-onset changes in Doppler ultrasonography parameters in fetal and fetomaternal circulation. ( $\mathrm{J}$ Turk Ger Gynecol Assoc 2015; 16: 80-5)

Keywords: Doppler ultrasonography, tocolysis, umbilical artery, uterine artery, middle cerebral artery

Received: 10 October, 2014

Accepted: 08 March, 2015

\section{Introduction}

There has been good news about rates of preterm birth in the United States. According to a preliminary study between 2006 and 2011 , it was determined that the rates have fallen down from $12.8 \%$ in 2006 to $11.7 \%$ in 2011 . The largest drop has been particularly observed in late preterm rates (34-36 weeks) (1). However, of course, in underdeveloped and developing countries, the condition is different. Improvements in assisted reproductive technology have caused an increase in the incidence of preterm labor (2). Preterm births accounts for $6 \%-10 \%$ of all births and is an important cause of perinatal mortality and morbidity (3). Preterm birth accounts for approximately two-thirds of neonatal mortality. In particular, in underdeveloped and developing countries, it causes serious social and economic loses (4). Therefore, it is important to prevent or delay preterm births to improve the perinatal outcome. This shows the importance of maternal corticosteroids and tocolytic treatments. In modern obstetrics, tocolytics play an important role in permitting the transfer of a pregnant patient to a tertiary care center and delaying birth for at least 48 hours. Thus, we can optimize the beneficial effects of corticosteroids to facilitate fetal pulmonary maturation, thereby decreasing complications such as necrotizing enterocolitis, intracranial bleeding, and respiratory distress syndrome (5).

In clinical practice, various pharmacological agents that inhibit uterine contractions are used. Tocolytic agents such as calcium channel blockers (nifedipine), beta-mimetics (ritodrine), and indomethacin may be used in cases of preterm labor in which uterine contractions cannot be controlled by intravenous hydration. These tocolytics can be used alone or in combinations (6). In general, maternal effects and side effects profiles of all these agents are known. However, their possible adverse effects on the fetus remain relatively unknown. There have only been limited data on tocolytics and their possible impacts on fetal and fetomaternal circulation (7). In the present study, we mainly aimed to determine the clinical side effects of nifedipine and ritodrine, mostly used tocolytic agents, and to evaluate their effects on the uterine arteries (UtAs), umbilical artery (UA), and middle cerebral artery (MCA) blood flow and Doppler ultrasonography parameters. Our secondary objective was to investigate the side effects of drugs. 


\section{Metarial and Methods}

Sixty pregnant women, who applied to our clinic because of preterm labor and were aged between 18 and 44 years, were included. The subjects were enrolled after institutional ethic committee approval. Informed consent was obtained from all participants. The research was conducted in women who fulfilled the following admission criteria: pregnant with a single fetus of 24-36-week gestation; fetus with intact amniotic membranes; and experiencing two or more painful and persistent uterine contractions in 10 minutes, as established by tococardiography. These contractions could not be controlled after 2 hours of bed rest and resulted in changes in the cervix (at least $2 \mathrm{~cm}$ cervical dilatation and $75 \%$ ripening) $(8,9)$. In all cases, fetal heart rates were recorded by ultrasonography or tococardiography. All patients included in the present study were in the latent phase of labor. Patients having cervical dilatation greater than $5 \mathrm{~cm}$ and effacement of $80 \%$ were not included in the present study. In addition, pregnant women with a concomitant morbidity such as heart, lung, or thyroid disease; high blood pressure; diabetes or infectious disease; an obstetric morbidity (e.g., pre-eclampsia, premature rupture of membranes, polyhydramniosis, gestational diabetes mellitus, intrauterine growth restriction, chorioanmionitis, or acute fetal distress); multiple pregnancies; or fetal malformations and patients who could not tolerate treatments were excluded from the present study. Demographic features and obstetric histories were recorded. Age, gravidity, parity, abortion, frequency of uterine contractions in 10 minutes, cervical dilatation, ripening parameters, and Bishop scores of patients were recorded. Fetal biometry and estimated fetal weight were evaluated via obstetric ultrasonography. Monitorization of uterine contractions and fetal cardiac activity were performed using a tococardiography device CMS 800G (Contec Medical System, China) or Wallach Sonicaid Team (Wallach Surgical devices, USA) for 20 minutes. Tocolysis was started when regular uterine contractions (5-7 contractions/20 minutes) were associated with cervical change. In patients whose gestational age was below 34 weeks, maternal corticosteroids were applied to facilitate fetal pulmonary maturation. Corticosteroid regimen included $12 \mathrm{mg}$ betamethasone or betamethasone disodiumphosphate (Celestone Chronodose, Schering-Eczacıbası ${ }^{\circledR}$, Lüleburgaz, Turkey) applied intramuscularly, repeated at 24-hour intervals. Doppler velocimetry measurements were performed 24 hours after corticosteroid administration.

In this investigation, patients with a diagnosis of preterm labor were randomized to receive either oral nifedipine (Nidilat ${ }^{\circledR}$, Santafarma, İstanbul, Turkey) $(\mathrm{n}=30)$ or intravenous ritodrine (Prepar® Zentiva, İstanbul, Turkey) $(n=30)$. Before and during tocolysis, the fetal heart rate, maternal blood pressure, maternal pulse rate were measured in 15-minute intervals in the loading dosage period and 4-hour intervals in the maintenance dosage period. Because we know that there is no consensus about the nifedipine regimen, the protocol used at our institution was carried out. Nifedipine was applied to patients in two dosage periods: loading and maintenance dosages. It consisted of an initial oral dose of $10 \mathrm{mg}$ nifedipine and three doses repeated at 20-minute intervals for 1 hour, while the maintenance regimen consisted of $10 \mathrm{mg}$ taken orally every 6 hours for further 24 hours (a total maximum dose of $60 \mathrm{mg}$ ). Nifedipine treatment was terminated after 48 hours in patients whose uterine contractions had stopped.

Ritodrine hydrochloride was applied intravenously (iv) as the tocolytic agent. The solution was prepared by titering $150 \mathrm{mg}$ ritodrine hydrochloride in $500 \mathrm{~mL} 5 \%$ dextrose to obtain a concentration of $0.3 \mathrm{mg} / \mathrm{mL}$. Infusion was started with a dose of $0.05 \mathrm{mg} / \mathrm{minute}$ (12 mL/hour), and it was increased to maximum $0.08 \mathrm{mg} /$ minute $(20 \mathrm{~mL} /$ hour$)$ progressively.

Drug infusion was continued at the rate at which uterine contractions of patients had stopped and terminated 12 hours after this. Cases in which uterine contractions had stopped in 2 hours of the initial dosage of drugs, were accepted as successful and treatment was continued. In patients whose contractions were not controlled by nifedipine or ritodrine, other tocolytic regimen protocols were used. This occurred in seven patients in nifedipine and six in ritodrine groups.

Therefore, new patients were randomly included instead of these 13 patients.

Doppler measurements were performed by the same operator using an Aloka alfa-10 ultrasound device (Hitachi Aloka Medikal Ltd., Tokyo, Japan) with a 5-MHz transabdominal probe. Doppler measurements were recorded after the fetal biometric measurements were performed. All measurements were repeated three times, and the mean values were taken by the same operator to obtain the minimal error factor. Doppler indices were measured before and at the beginning, 2 hours (early period), and 48 hours (late period) of tocolysis. Because the contractions affect UtA Doppler indices, measurements before tocolysis were performed in periods between contractions with the patient positioned in a semi-Fowler position to avoid orthostatic hypotension. The systole/diastole (S/D) ratio, pulsatility index (PI), and resistance index (RI) of UA and UtA as well as peak systolic velocity (PSV) of MCA was measured. UA measurement was performed on the free loop of the cord, more than $4 \mathrm{~cm}$ apart from the placental and fetal insertion site, and the mean was taken. UtA measurement was performed on both the right and left side at the point medial to the iliac artery and at the isthmus level where UtAs could be observed. UA and UtA Doppler parameter measurements were performed after visualizing five heart cycles. Three different heart cycles were measured, and their means were taken. MCA measurements could be performed by visualizing Willis polygone with Color Doppler ultrasonography, and one of MCAs (only anterior or posterior) was used for the study. Scans of the vessels were obtained during fetal inactivity, during periods of apnea, and in the absence of uterine contractions.

In the present study, neonatal parameters of Apgar score after 1 and 5 minutes as well as birth and placental weights were measured and complications such as fetal respiratory distress syndrome, necrotizing enterocolitis, intracranial hemorrhage, and fetal infections were recorded.

An a priori sample size calculation was performed with an $\alpha$ of 0.05 and a $\beta$ of 0.20 on the basis of an estimated cere- 
broplacental ratio of $2.06 \pm 0.5$ between 27 and 33 gestational weeks. It was estimated that a total sample size of 25 pregnant women would be required to reveal a difference of 0.5 in the cerebroplacental ratio before and after treatment. In total, 30 participants were included in each group for power of research. Statistical analyses were performed by employing the Statistical Package for Social Sciences software 13.0 for Windows package software (SPSS Inc., Chicago, IL, USA). The descriptive statistical method used in the present study was analysis of covariance (ANCOVA). Comparative analysis between groups was performed by Student's t test. Side effects of tocolytic agents were analyzed by chi-square test and Fischer's exact test wherever appropriate to determine significance. Results were evaluated in terms of the $95 \%$ confidence interval, and p value $<0.05$ was accepted as significant.

\section{Results}

Sixty pregnant patients with preterm labor were included. Demographic properties of patients in nifedipine and ritodrine groups were similar (Table 1). In patient evaluations, there was no statistical difference in laboratory results of groups examined before and 48 hours after tocolytic treatments ( $p>0.05)$. In the present study, effects of tocolytic drugs on time to delivery were evaluated. In both groups, time to delivery was 11 days. There was no statistical difference in time to delivery between nifedipine and ritodrine groups ( $\mathrm{p}>0.05$ ). Besides, arterial blood pressure of participants was measured at 48 hours of treatment, and there was no statistical difference between groups ( $p>0.05)$. Because both drugs may have effects on the vascular area by arterial blood pressure or uteroplacental blood flow, 1-minute and 5-minute Apgar scores, birth weights, and placental weights of participants between groups were compared. There was no statistical difference between groups ( $p>0.05)$. Clinical parameters of cases are also shown in Table 1.

In the study, 47 (84\%) patients gave birth vaginally and 13 (26\%) patients gave birth by the cesarean section. In eight patients in the nifedipine group and five in the ritodrine group gave birth by the cesarean section. Major indications of the cesarean section were anomalous presentation, previous cesarean section, cephalopelvic disproportion, and fetal distress.

In the present study, fetal complications after labor were evaluated in both the groups. There was no case of neonatal sepsis, necrotizing enterocolitis, grade $3 / 4$ intraventriculer hemorrhage, respiratory distress syndrome, and perinatal death in the groups. However, two neonates in the ritodrine group and one in the nifedipine group had transient tachypnea.

Maternal complications in treatment groups are shown in Table 2. The most commonly observed side effect of ritodrine was tachycardia. It was observed in $73.3 \%$ of patients. Headache, nauseavomiting, dyspnea, anxiety, and chest pain were the other side effects. In the nifedipine group, tachycardia was observed in $20 \%$ and headache was the other most common side effect (13.3\%). Tachycardia and anxiety were more commonly observed in the ritodrine group $(\mathrm{p}<0.05)$.

In present study, blood flow patterns of nifedipine and ritodrine in UA, UtA, and MCA before, 2 hours after, and 48 hours after
Table 1. Demographic parameters and clinical characteristics of patients

\begin{tabular}{|l|c|c|c|}
\hline & $\begin{array}{c}\text { Nifedipine } \\
(\mathbf{n = 3 0 )} \\
\text { (mean } \pm \text { SD) }\end{array}$ & $\begin{array}{c}\text { Ritodrine } \\
(\mathbf{n = 3 0 )} \\
(\mathbf{m e a n} \pm \text { SD) }\end{array}$ & $\mathbf{p}$ \\
\hline Age (years) & $26.9 \pm 5.71$ & $27.4 \pm 5.85$ & 0.73 \\
\hline Gestational age (weeks) & $32.9 \pm 2.02$ & $32.4 \pm 2.09$ & 0.35 \\
\hline Gravidity & $1.86 \pm 1.16$ & $2.23 \pm 1.04$ & 0.20 \\
\hline Parity & $1.76 \pm 0.93$ & $2.03 \pm 1.06$ & 0.30 \\
\hline Primiparity (\%) & $7(\% 23.3)$ & $10(\% 33.3)$ & 0.56 \\
\hline Time to delivery (days) & $11.50 \pm 1.61$ & $11.26 \pm 2.09$ & 0.63 \\
\hline 1-minute Apgar score & $7.13 \pm 0.77$ & $7.13 \pm 0.73$ & 1.00 \\
\hline 5-minute Apgar score & $8.10 \pm 0.71$ & $8.23 \pm 0.67$ & 0.46 \\
\hline Birth weight (g) & $1989 \pm 288$ & $2000 \pm 293$ & 0.89 \\
\hline Placental weight (g) & $363 \pm 57$ & $359 \pm 62$ & 0.79 \\
\hline $\begin{array}{l}\text { Mean arterial blood } \\
\text { pressure (mmHg) }\end{array}$ & $89.80 \pm 6.12$ & $87.58 \pm 5.36$ & 0.14 \\
\hline *Statistical Significance: $\mathrm{p}<0.05$ & & & \\
\hline
\end{tabular}

Table 2. Maternal complications in treatment groups

\begin{tabular}{|l|c|c|c|}
\hline & $\begin{array}{c}\text { Ritodrine } \\
(\mathbf{n = 3 0 )} \\
(\mathbf{n}-\%)\end{array}$ & $\begin{array}{c}\text { Nifedipine } \\
(\mathbf{n = 3 0 )} \\
(\mathbf{n}-\%)\end{array}$ & $\mathbf{p}$ \\
\hline Tachycardia & $22(73.3 \%)$ & $6(20 \%)$ & 0.001 \\
\hline Emesis and vomiting & $4(13.3 \%)$ & $1(3.3 \%)$ & 0.161 \\
\hline Anxiety & $4(13.3 \%)$ & - & 0.03 \\
\hline Dyspnea & $1(3.3 \%)$ & - & 0.31 \\
\hline Chest pain & $1(3.3 \%)$ & - & 0.31 \\
\hline Pulmonary edema & - & - & $>0.05$ \\
\hline Headache & $1(3.3 \%)$ & $4(13.3 \%)$ & 0.16 \\
\hline Skin rashes & - & $1(3.3 \%)$ & 0.31 \\
\hline *Statistical significance: $\mathrm{p}<0.05$ & \multicolumn{3}{|l}{} \\
\hline
\end{tabular}

tocolysis were recorded. For both the drugs, the Doppler findings of different arteries with time were compared. Besides, in each drug, the changes in blood flow patterns with time were compared. In both the groups, early- and late-onset changes in Doppler indices for UA, UtA, and MCA were similar. In addition, there was no significant difference in Doppler indices with time after the application of each drug ( $p>0.05$, Table 3$)$.

\section{Discussion}

In the present study, it was determined that nifedipine and ritodrine used as tocolytic agents did not significantly alter earlyand late-onset changes in Doppler ultrasonography parameters in fetal and fetomaternal circulation. Various pharmacological agents have been used for tocolysis in preterm labor. Although we know much about pharmacokinetics and pharmacodynamics of these drugs, there are limited data about their effects on fetal and fetomaternal circulation (10). 
Table 3. Doppler measurements of UA, UtA, and MCA before, 2 and 48 hours after tocolytic treatments (ANCOVA)

\begin{tabular}{|c|c|c|c|c|c|c|c|c|c|c|}
\hline \multirow[b]{2}{*}{ UA } & \multicolumn{3}{|c|}{ Ritodrine } & \multicolumn{4}{|c|}{ Nifedipine } & \multicolumn{3}{|c|}{$\mathbf{p}$} \\
\hline & 0 hour & 2 hours & 48 hours & 0 hour & 2 hours & 48 hours & SEM & D & $\mathrm{T}$ & DxT \\
\hline PI & 1.01 & 0.92 & 0.93 & 1.00 & 0.96 & 0.97 & 0.03 & 0.49 & 0.25 & 0.74 \\
\hline RI & 0.62 & 0.60 & 0.60 & 0.62 & 0.61 & 0.61 & 0.01 & 0.55 & 0.24 & 0.87 \\
\hline$S / D$ & 2.77 & 2.61 & 2.58 & 2.73 & 2.59 & 2.63 & 0.08 & 0.98 & 0.13 & 0.84 \\
\hline \multicolumn{11}{|c|}{ Right Ut A } \\
\hline PI & 0.84 & 0.80 & 0.87 & 0.81 & 0.84 & 0.80 & 0.04 & 0.62 & 0.96 & 0.45 \\
\hline RI & 0.53 & 0.52 & 0.53 & 0.51 & 0.54 & 0.51 & 0.01 & 0.69 & 0.89 & 0.43 \\
\hline $\mathrm{S} / \mathrm{D}$ & 2.25 & 2.17 & 2.20 & 2.11 & 2.27 & 2.17 & 0.09 & 0.75 & 0.93 & 0.44 \\
\hline \multicolumn{11}{|c|}{ Left Ut A } \\
\hline PI & 0.86 & 0.84 & 0.86 & 0.83 & 0.82 & 0.83 & 0.05 & 0.52 & 0.95 & 0.99 \\
\hline RI & 0.55 & 0.53 & 0.54 & 0.53 & 0.52 & 0.56 & 0.01 & 0.74 & 0.52 & 0.69 \\
\hline $\mathrm{S} / \mathrm{D}$ & 2.37 & 2.30 & 2.43 & 2.26 & 2.24 & 2.39 & 0.12 & 0.50 & 0.51 & 0.95 \\
\hline \multicolumn{11}{|c|}{ MCA } \\
\hline PI & 1.76 & 1.74 & 1.73 & 1.85 & 1.81 & 1.86 & 0.06 & 0.07 & 0.83 & 0.91 \\
\hline $\mathrm{RI}$ & 0.83 & 0.80 & 0.81 & 0.84 & 0.83 & 0.82 & 0.01 & 0.05 & 0.14 & 0.76 \\
\hline $\mathrm{S} / \mathrm{D}$ & 6.05 & 6.08 & 6.20 & 6.72 & 6.610 & 6.25 & 0.40 & 0.22 & 0.91 & 0.72 \\
\hline PSV & 42.90 & 44.64 & 44.02 & 42.90 & 43.13 & 44.01 & 0.50 & 0.22 & 0.05 & 0.22 \\
\hline
\end{tabular}

Doppler ultrasonography is mostly used to evaluate blood flow. In recent perinatology practice, Doppler ultrasonography has been used to determine fetal well-being, particularly in intrauterine growth retardation and fetal anemia, and it plays an important role in planning the treatment of these conditions. In addition, it is known that Doppler ultrasonography is used to evaluate the effects of tocolytic drugs, which have side effects on the cardiovascular system, uteroplacental blood flow, and the fetal vascular system. UtA, UA, and MCA are most commonly studied arteries to evaluate fetal well-being (6).

There are some controversies about the tocolytic usage of nifedipine because there are limited data about potential harmful effects of the drug on uteroplacental perfusion and fetal oxygenation (11). It blocks calcium channels and inhibits smooth muscle contraction. Thus, it decreases uterine vascular resistance (12). It passes through the placenta. Therefore, this vasodilatation effect of the drug raises doubts about the potential effects on the fetal circulatory system (13). Studies about nifedipine on animals have led to contradictory results. In literature, there are limited numbers of studies about Doppler ultrasonography investigations on pregnant women receiving tocolytic treatments. Guclu et al. (14) designed a study involving 21 pregnant women receiving nifedipine as a tocolytic agent. In that study, no significant difference was found in Doppler ultrasonography measurements of UA and fetal MCAs before and 3 hours after treatment. In another study, no difference was found in Doppler measurement parameters (PI and RI) in UA before and 3 hours after drug application (15). In our study, we did not find any significant difference in Doppler ultrasonography parameters for UA, UtA, and MCA before and 2 hours (early) after nifedipine treatment. This result showed that the nifedipine loading dosage (30 $\mathrm{mg}$ ) and maintenance dosage $(10 \mathrm{mg}$ ) repeated in the 6 -hour period ( $40 \mathrm{mg} /$ day) in the early phase did not cause any unfavorable effects on uteroplacental blood flow and the fetal vascular system. In a study on late-term effects of nifedipine, the PI value of UA did not change but the PI value of UtA and MCA significantly decreased 24-48 hours after treatment (16). In that study, it was found that nifedipine caused distinctive redistribution in the fetal vascular system and changed the cerebral blood flow (7). In our study, we found no statistically significant difference between PI and other Doppler indices for UA, UtAs, and MCA at 48h (late phase) and before $2 \mathrm{~h}$ (early phase) after treatment. This indicated that nifedipine did not cause any late harmful effect on the fetal vascular system, fetal cerebral system, and uteroplacental blood flow. Of course, this is a preliminary result and should be supported by comprehensive studies including a high number of cases.

The application of ritodrine, a beta-mimetic agent, has been certificated in the 1980s. Ritodrine and its conjugates pass through the placenta, incorporate into fetal circulation, and are therefore found in the same concentration in both fetal and maternal plasma compartments $(17,18)$. This indicates that ritodrine can directly affect fetal circulation. In the study of Gokay et al. (18), the utilization of ritodrine as a tocolytic agent caused an increase in the PI value of MCA but a decrease in the PI value of UA (18). In another study of Rasanen, ritodrine led to a decrease in the PI value of MCA but did not cause any variation in Doppler parameters of UA (19). Ritodrine applied to maternal circulation directly affects the perfusion pressure of the fetus, in proportion with the dosage (20). Therefore, discrepancies in Doppler 
parameter findings of the two studies are probably because of the application of different dosages of the drug. Gokay et al. (18) used the dosage of $350 \mathrm{mcg} / \mathrm{minute}$, while Rasanen applied 200 $\mathrm{mcg} / \mathrm{minute}$ at the maximum level. These results indicated that the dosage of the drug may directly affect variations in Doppler parameters and fetomaternal blood flow. In our study, ritodrine infusion started at dosage of $50 \mathrm{mcg} /$ minute and increased to the basal dose at which uterine contractions had stopped. The maximum dosage was $125 \mathrm{mcg} / \mathrm{minute}$. There was no statistical difference in Doppler indices of UA and both UtA and MCA, before, 2 hours after (early period) and 48 hours after (late period) ritodrine treatment. These results indicated that the application of ritodrine as a tocolytic agent did not cause any variation in uteroplacental blood flow and the fetal vascular system before as well as in the early and late periods of treatment. The discrepancy in the results of our study compared with those of other studies was probably because of an increase in the dosage in a progressive and controlled manner. In addition, the maximum dosage used in our research was less than the dosages used different studies. In a study of Sayın, ritodrine application did not cause any change in Doppler parameters of UA and MCA in 48 hours of treatment in pregnant women at 26-32 gestation weeks. On the other hand, changes of Doppler parameters in UA and MCA were observed after 48 hours of treatment and in pregnant women at 32-36 gestation weeks (21). In another study, similar to this, Doppler parameters of UA and MCA changed 48 hours after ritodrine treatment (22). Although changes in Doppler parameters due to ritodrine application were mostly observed after 32 weeks of gestation, in our study, cases included were predominantly between 26-32 weeks of gestation. Therefore, these controversies about impacts of ritodrine can be explained by different gestational weeks of pregnant women included in different studies.

In the perspective of literature, this investigation pointed out that nifedipine was a safe drug and that this drug did not cause any variation in Doppler parameters, indicating unfavorable effects on fetal and fetomaternal circulation at standard dosages. However, randomized controlled studies including a large number of cases are required to evaluate the effects on high dosages. Ritodrine was shown to be a safe tocolytic agent in short-lasting applications (<48 hours) and in 26-32 weeks of gestation. However, we must be cautious, particularly in longlasting administrations ( $>48$ hours) after 32 weeks of gestation. Therefore, large randomized posology researches including a high number of cases with different gestational ages are required to demonstrate the impressions of drugs on fetal and fetomaternal circulation.

Finally, it is obligatory to emphasize the situation of betamethasone, which is important for fetopulmonary maturation and mostly used in combination with tocolytic agents in preterm labor, while discussing results of our study on effects of nifedipine and ritodrine on fetal and fetomaternal circulation. There are too many investigations and many different results on effects of betamethasone on Doppler indices of fetal and fetomaternal circulation. In animal models, it did not affect the maternal heart rate and blood pressure increased fetal blood pressure (23). It had mild effect on the fetal heart rate (24). Although in some investigations, it was found that it did not affect Doppler parameters of UA, UtA, and MCA, in some, a decrease in Doppler indices of UA and MCA $(25,26)$ and ductus venosus, particularly PI of MCA, was seen (27). Therefore, it is thought that variations in fetal and fetomaternal circulation in the late period (24-48 hours) of nifedipine and ritodrine in different studies are caused by a combined effect of tocolysis and betamethasone.

In conclusion, nifedipine and ritodrine used as tocolytic agents did not cause any early- and late-onset change in Doppler ultrasonography parameters of fetal and fetomaternal circulation. Because the efficiency and vascular side effects of both drugs were similar, the side effect profile, cost-effectiveness, clinical efficacy, and patient compliance to treatment must be important in selecting the tocolytic agent, and nifedipine seems to be more preferable in tocolytic treatment of preterm labor.

Ethics Committee Approval: Ethics committee approval was received for this study from the ethics committee of Atatürk University in 2007.

Informed Consent: Written informed consent was obtained from patients who participated in this study.

Peer-review: Externally peer-reviewed.

Author Contributions: Concept - B.Ö.B.; Design - B.Ö.B.; Supervision - B.Ö.B., S.N.A.; Resource - S.N.A., B.Ö.B.; Materials - B.Ö.B.; Data Collection \& /or Processing - B.Ö.B., S.N.A.; Analysis \& /or Interpretation - S.N.A.; Literature Search - S.N.A., B.Ö.B.; S.N.A., B.Ö.B.; Critical Reviews - S.N.A.

Conflict of Interest: No conflict of interest was declared by the authors.

Financial Disclosure: The authors declared that this study has received no financial support.

\section{References}

1. Hamilton BE, Martin JA, Ventura SJ. Births: preliminary data for 2012. Natl Vital Stat Rep 2013; 62: 1-20.

2. Stoinic J, Radunovic N, Jeremic K, Kolica Bk, Mitroyic M, Tulic I. Perinatal outcome of singleton pregnancies following in vitro fertilization. Clin Exp Obstet Gynecol 2013; 40: 277-83.

3. Arias F, Rodriquez L, Rayne SC, Kraus FT. Maternal placental vasculopathy and infection: two distinct subgroups among patients with preterm labor and preterm ruptured membranes. Am J Obstet Gynecol 1993; 168: 585-91. [CrossRef]

4. Gilbert WM. The cost of preterm birth: the low cost versus high value of tocolysis. BJOG 2006; 113 (Suppl 3): 4-9. [CrossRef]

5. Spong CY. Prediction and prevention of recurrent spontaneouspreterm birth. Obstet Gynecol 2007; 110 (2 Pt 1): 405-15. [CrossRef]

6. Cararach V, Palacio M, Martínez S, Deulofeu P, Sánchez M, Cobo T, Coll $\mathrm{O}$. Nifedipine versus ritodrine for suppression of preterm labor Comparison of their efficacy and secondary effects. Eur J Obstet Gynecol Reprod Biol 2006; 127: 204-8. [CrossRef]

7. Guclu S, Gol M, Saygılı U, Demir N, Sezer O, Baschat AA. Nifedine therapy for preterm labor:effects on placental, fetal cerebral and atrioventricular Doppler parameters in the first 48 hours. Ultrasound Obstet Gynecol 2006; 27: 403-8. [CrossRef] 
8. Creasy RK. Preterm labor and delivery: Maternal fetal medicine 3. Edition. Philadelphia: W.B. Saunders Company; Ch 33. 1994: 494.

9. Guinn DA, Goepfert AR, Owen J, Brumfield C, Hauth JC. Management options in women with preterm uterine contractions. A randomized trial. Am J Obstet Gynecol 1997; 177: 814. [CrossRef]

10. Haram K, Mortensen JH, Wollen AL. Preterm delivery: an overwiew. Acta Obstet Gynecol Scand 2003; 82: 687-704. [CrossRef]

11. Glock JL, Morales WJ. Efficacy and safety of nifedipine versus magnesium sulfate in the management of preterm labor: a randomized study. Am J Obstet Gynecol 1993; 169: 960-4. [CrossRef]

12. Braunwald E. Mechanisms of action of calcium-channel-blocking agents. N Engl J Med 1982; 307: 1618-27. [CrossRef]

13. Magee LA, Schick B, Donnenfeld AE, Sage SR, Conover B, Cook L, McElhatton PR, et al. The safety of calcium channel blockers in human pregnancy: a prospective, multicenter cohort study. Am J Obstet Gynecol 1996; 174: 823-8. [CrossRef]

14. Guclu S, Gol M, Doğan E, Demir N, Baschat AA. The short term effect of nifedipine tocolysis on placental, fetal cerebral and atrioventricular Doppler waveforms. Ultrasound Obstet Gynecol 2004; 24: 761-5. [CrossRef]

15. Garcia-Velasco JA, Gonzalez A. A prospective, randomized trial of nifedipine vs. ritodrine in threatened preterm labor. Int $\mathrm{J}$ Gynecol Obstet 1998; 61: 239-44. [CrossRef]

16. Stan CM, Boulvain M, Pfister R, Hirsbrunner-Almagbaly P. Hydration for treatment of preterm labour. Cochrane Database Syst Rev 2013; 11: CD003096. [CrossRef]

17. Brashear WT, Kuhnert BR, Wei R. Maternal and neonatal urinary excretion of sulfate and glucuronide ritodrine conjugates. Clin Pharmacol Ther 1988; 44: 634-41. [CrossRef]

18. Gokay Z, Ozcan T, Copel JA. Changes in fetal hemodynamics with ritodrine tocolysis. Ultrasound Obstet Gynecol 2001; 18: 44-6. [CrossRef]
19. Rasanen J. The effects of Ritodrine infusion on fetal myocardial function and fetal hemodynamics. Acta Obstet Gynecol Scand 1990; 69: 487-92. [CrossRef]

20. Ohashi M, Asai M, Maeda K, Suzuki M, Noguchi M, Nakanishi M. Effect of ritodrine hydrochloride on fetal perfusion pressure in dually perfused human placenta. Nippon Sanka Fujinka Gakkai Zasshi 1995; 47: 237-42.

21. Sayin C, Arda S, Varol FG, Süt N. The effects of ritodrine and magnesium sulfate on maternal and fetal Doppler blood flow patterns in women with preterm labor. Eur J Obstet Gynecol Reprod Biol 2010; 152: 50-4. [CrossRef]

22. Kulak N, Türkücüoğlu I, Kafkaslı A. Tokolitik Tedavinin Umbilikal, Uterin ve Spiral Arter Doppler Bulgularına Etkisi. Perinatoloji Dergisi 2007; 15: 93-145.

23. Koenen SV, Mecenas CA, Smith GS, Jenkins S, Nathanielsz PW. Effects of maternal betamethasone administration on fetal and maternal blood pressure and heart rate in the baboon at 0.7 of gestation. Am J Obstet Gynecol 2002; 186: 812-7. [CrossRef]

24. Lunshof MS, Boer K, Wolf H, Koppen S, Velderman JK, Mulder EJ. Shortterm $(0-48 \mathrm{~h})$ effects of maternal betamethasone administration on fetal heart rate and its variability. Pediatr Res 2005; 57: 545-9. [CrossRef]

25. Deren O, Karaer C, Onderoglu L, Yigit N, Durukan T, Bahado-Singh RO. The effect of steroids on the biophysical profile and Doppler indices of umbilical and middle cerebral arteries in healthy preterm fetuses. Eur J Obstet Gynecol Reprod Biol 2001; 99: 72-6. [CrossRef]

26. Chitrit Y, Caubel P, Herrero R, Schwinte AL, Guillaumin D, Boulanger MC. Effects of maternal dexamethasone administration on fetal Doppler flow velocity waveforms. BJOG 2000; 107: 501-7. [CrossRef]

27. Kahler C, Schleussner E, Moller A, Seewald HJ. Doppler measurements in fetoplacental vessels after maternal betamethasone administration. Fetal Diagn Ther 2004; 19: 52-7. [CrossRef] 